\title{
Protogenin prevents premature apoptosis of rostral cephalic neural crest cells by activating the $\alpha 5 \beta 1$-integrin
}

\author{
Y-C Wang ${ }^{1}$, H-C Juan ${ }^{2}$, Y-H Wong ${ }^{1}$, W-C Kuo ${ }^{2}$, Y-L Lu' ${ }^{1}$, S-F Lin ${ }^{3}$, C-J Lu' ${ }^{1}$ and M-J Fann ${ }^{\star 2,4}$
}

The bones and connective tissues of the murine jaws and skull are partly derived from cephalic neural crest cells (CNCCs). Here, we report that mice deficient of protogenin (Prtg) protein, an immunoglobulin domain-containing receptor expressed in the developing nervous system, have impairments of the palatine and skull. Data from lineage tracing experiments, expression patterns of neural crest cell (NCC) marker genes and detection of apoptotic cells indicate that the malformation of bones in Prtgdeficient mice is due to increased apoptosis of rostral CNCCs (R-CNCCs). Using a yeast two-hybrid screening, we found that Prtg interacts with Radil, a protein previously shown to affect the migration and survival of NCCs in zebrafish with unknown mechanism. Overexpression of Prtg induces translocation of Radil from cytoplasm to cell membrane in cultured AD293 cells. In addition, overexpression of Prtg and Radil activates $\alpha 5 \beta 1$-integrins to high-affinity conformational forms, which is further enhanced by the addition of Prtg ligand ERdj3 into cultured cells. Blockage of Radil by RNA interference abolishes the effect of ERdj3 and Prtg on the $\alpha 5 \beta 1$-integrin, suggesting that Radil acts downstream of Prtg. Prtg-deficient R-CNCCs display fewer activated $\alpha 5 \beta 1$-integrins in embryos, and these cells show reduced migratory ability in in vitro transwell assay. These results suggest that the inside-out activation of the $\alpha 5 \beta 1$-integrin mediated by ERdj3/Prtg/Radil signaling is crucial for proper functions of R-CNCCs, and the deficiency of this pathway causes premature apoptosis of a subset of R-CNCCs and malformation of craniofacial structures.

Cell Death and Disease (2013) 4, e651; doi:10.1038/cddis.2013.177; published online 6 June 2013

Subject Category: Neuroscience

Congenital craniofacial defects are the most common birth defects in human. Many craniofacial syndromes, such as the Collins, Robin and Di George syndromes, are associated with defects in neural crest (NC) development. ${ }^{1}$ In rodents, jaws and the skull vault are derived from the cephalic NC cells (CNCCs) and the head paraxial mesoderm cells. ${ }^{2}$ In the mouse embryo, the rostral CNCCs (R-CNCCs) originate from $\mathrm{NC}$ between diencephalon to rhombomere 2 (r2) and undergo an epithelial-mesenchymal transition at embryonic day 8.5 (E8.5), colonize the frontonasal primordium and branchial arch 1 (BA1) at E9-9.5 and later give rise to the skull, the frontonasal skeleton and anterior part of the lower jaw. . $^{3,4}$ Originated from NC between $\mathrm{r} 4$ and $\mathrm{r} 8$, caudal CNCCs (C-CNCCs) enter into BA2-6 and form connective tissues, smooth muscle cells and the pericytes of the blood vessels within the neck and cardiovascular structures. ${ }^{5,6,7}$ Notably, trunk NC cells (TNCCs) do not form skeletal tissues. In addition to CNCCs, a part of posterior skull vault and the majority of skeletons in posterior upper jaw are contributed by derivatives of head paraxial mesoderm. ${ }^{8}$
It has been shown that integrins are critical molecules for proper development of NC cells (NCCs), and perturbation of integrin molecules may lead to immobility and apoptosis of NCCs. Bronner-Fraser showed that neutralization of antibodies against the $\beta 1$-integrin reduces $\mathrm{R}-\mathrm{CNCC}$ migration in chick embryos. ${ }^{9,10}$ Blockage of multiple integrins containing $\beta 1$ and $\alpha 3$ subunits inhibits migration of cultured avian TNCCs. ${ }^{11}$ Similarly, expression of the $\alpha 5 \beta 1$-integrin is required for Xenopus CNCC migration on fibronectin ${ }^{12}$ and there is an increase of cell death of migrating CNCCs in the $\alpha 5$-integrin-deficient mice. ${ }^{13}$ In addition, conformational changes of the extracellular domain of integrin heterodimers is another regulatory step for integrin effects on NCC development. ${ }^{14}$ However, how integrin conformation in NCCs is modulated remains unknown.

Many immunoglobulin family members are expressed in the developing nervous system with undefined functions. Here, we explore functions of one immunoglobulin family member, namely protogenin (Prtg) protein. Prtg protein is restrictedly expressed between E7 and E10 in mouse embryo and acts as

\footnotetext{
${ }^{1}$ Institute of Neuroscience, National Yang-Ming University, Taipei, Taiwan 112, Republic of China; ${ }^{2}$ Department of Life Sciences and Institute of Genome Sciences, National Yang-Ming University, Taipei, Taiwan 112, Republic of China; ${ }^{3}$ Instrumentation Resource Center, National Yang-Ming University, Taipei, Taiwan 112, Republic of China and ${ }^{4}$ Brain Research Center, National Yang-Ming University, Taipei, Taiwan 112, Republic of China

${ }^{*}$ Corresponding author: M-J Fann, Department of Life Sciences and Institute of Genome Sciences, National Yang-Ming University, No.155, Sec. 2, Linong Street, Taipei, Taiwan 112, Republic of China. Tel: +886 22826 7184; Fax: +886 22823 4898; E-mail: mjfann@ym.edu.tw

Keywords: Radil; branchial arches; bone formation; integrin

Abbreviation: BA, branchial arch; CM, conditioned medium; CNCCs, cephalic neural crest cells; C-CNCCs, caudal cephalic neural crest cells; E8.5, embryonic day 8.5; NC, neural crest; NCCs, neural crest cells; non-TNCCs, trunk non-neural crest cells; Prtg, protogenin; Prtg-f, full-length Prtg; Prtg-c, Prtg cytoplasmic domain; Prtg $\Delta c$, cytosolic domain-deleted Prtg; r2, rhombomere 2; RC, rostral cephalic; R-CNCCs, rostral cephalic neural crest cells; R-non-CNCCs, rostral non-cephlaic neural crest cells; TNCCs, trunk neural crest cells; TUNEL, terminal deoxynucleotidyl transferase dUTP nick-end labeling

Received 07.12.12; revised 26.3.13; accepted 29.4.13; Edited by A Verkhratsky
} 
a receptor by binding its ligand ERdj3. ${ }^{15}$ Although many activities of Prtg have been demonstrated in vitro and in chick embryos, ${ }^{15-17}$ roles of Prtg during mouse development are still unclear. In this study, we generated conventional Prtg knockout mutant mice. Defects of the craniofacial structure are observed in the neonatal Prtg mutants. We demonstrate that the defective skeletal phenotypes are due to abnormal apoptosis of R-CNCCs at E9-E10. The participating molecules involved in Prtg signaling include Radil and high-affinity conformational forms of the $\alpha 5 \beta 1$-integrin.

\section{Results}

Generation of Prtg knockout mice. A targeting vector that replaces exons 3-7 of the Prtg gene with the IRES-lacZ gene upon homologous recombination was generated (Figure 1a). Insertion of IRES-lacZ into the Prtg genome creates a premature termination of the Prtg protein and results in a peptide containing only the first 137 amino acids out of total 1192 amino acids. Germline transmission of the targeted allele was verified by Southern blotting (Figure 1b). No fulllength Prtg (Prtg-f) protein is expressed in homozygous mice and about half of the amount of Prtg protein is present in heterozygous mice (Figure 1c). Results from immunofluoresence staining confirm that no Prtg protein is expressed in homozygous mice (Figure 1d).

Prtg $^{-1-}$ mice have abnormality of craniofacial skeletons and cartilages. Heterozygous $\mathrm{Prtg}^{+/-}$mice are morphologically normal and fertile. The mating between heterozygous $\mathrm{Prtg}^{+/-}$mice produces $\mathrm{Prtg}^{-/-}$homozygous neonates that are born with a normal Mendelian ratio, but have a higher mortality. In all, $44.4 \%$ of neonatal $\mathrm{Prtg}^{-/-}$homozygous mice die within $72 \mathrm{~h}$ of birth. Another $11.1 \%$ of Prtg $^{-/-}$mice exhibit growth retardation and die before postnatal day 14 ; this is apparently due to malnutrition, which is revealed by smaller body sizes and delayed body-weight gain (data not shown). The remaining Prtg $\mathrm{Pr}^{-}$ mutants survive to adulthood and are fertile. The progeny from mating between homozygous mice still exhibits the $\sim 45 \%$ mortality rate within the first 3 days. We thus focused on finding the defects that are responsible for the death of the $\mathrm{Prtg}^{-/-}$mutants within $72 \mathrm{~h}$ after birth.

As neonatal homozygotes have lower amounts or no milk in their stomachs (Figure 1f), we examined the enteric nervous system by measuring acetylcholinesterase activity in P1 gastrointestinal tract. There is no apparent difference of neuronal innervation in the intestine between the wild-type and $\mathrm{Prtg}^{-1-}$ mice (Figures $1 \mathrm{~g}$ and $\mathrm{h}$ ). Examination of the developing nervous system in E10.5 embryos by wholemount staining using antibody against 165-kDa neurofilament reveals no abnormalities in the Prtg $^{-/-}$embryos (Figure 1j). The gross morphology of the cerebral cortex, hippocampus, eye, olfactory bulb, cerebellum and spinal cord in P1 $\mathrm{Prtg}^{-1-}$ mutants is normal by eosin and hematoxylin staining (data not shown).

Defective nasal structures including the palatal bones and/ or nasal septum may bring about ingestion difficulty and/or a respiration deficiency, causing the death of the neonatal $\mathrm{Prtg}^{-/-}$pups. Thus, we examined the cranial bones and cartilage of the P1 $\mathrm{Prtg}^{-/-}$mutants with Alizarin red and Alcian blue staining. The Prtg ${ }^{-/-}$mutants are found to have a shorter and thinner nasal septum (black-dotted circle in Figure 1I). In some severe cases, there is no nasal septum. Incomplete fusion of the basisphenoid bone is also observed in the Prtg knockout mice (arrow in Figure 1l). In addition, the palatine of the $\mathrm{Prtg}^{-/-}$mice is found to be thinner (arrow in Figure $1 \mathrm{~m}$ ). Furthermore, the Prtg ${ }^{-/-}$mutants displayed a loss of branches of the ala temporalis and less mineralization of the parietal bone, temporal bone and supraoccipital bone (Figures $1 p$ and $r$ ). The penetrance of skeletal defects ranges from 42.8 to $61.1 \%$ (Figure 1s). It is noted that all survived mutant pups contain normal nasal septum and palatine when examined at P4, suggesting that the cause of perinatal death is likely due to defects of these two structures.

Fewer rostral CNCCs are present in the Prtg $^{-1-}$ mouse embryos. The observed craniofacial defects of $\mathrm{Prtg}^{-1-}$ mutants are in structures that are developmentally derived from R-CNCCs and head paraxial mesoderm (Figure 1s). We conducted lineage tracing experiments by generating $\mathrm{Prtg}^{-1-}$ mutants with a Wnt1-Cre;R26R genetic background in which the NC-derived cells are marked with $\beta$-galactosidase. ${ }^{18,19}$ When Prtg $^{-1-} ;$ Wnt1-Cre;R26R embryos were examined at E10.5, fewer $\mathrm{X}$-gal ${ }^{+}$cells were detected in the diencephalon, mesencephalon and frontonasal primordium compared wih those in the heterozygous embryos (arrowheads in Figures $2 a$ and $b, n=6$ for each genome type). In addition, there are also fewer $\mathrm{X}$-gal ${ }^{+}$cells in dorsal midbrain, frontonasal process and upper jaw region

Figure 1 Abnormalities of the craniofacial bones in Prtg $^{-/-}$mice. (a) Schematic diagrams depicting the targeting vector, Prtg locus and the predicted recombinant allele. (b) Germline transmission of the targeted allele was verified by Southern blotting. The expected sizes of the DNA fragments are marked (arrowheads). WT: wild type; Mut: mutant. (c) Tissue extracts of E9.5 wild-type, Prtg ${ }^{+1-}$ and Prtg ${ }^{-1-}$ embryos were subjected to western blot analysis using anti-Prtg antibody. (d) Results from immunofluorescence staining of Prtg protein (red) in transverse sections of E9.5 Prtg ${ }^{-/-}$embryos demonstrate no expression of Prtg protein in Prtg ${ }^{-/-}$embryos. $^{-1}$ Nuclei are labeled with DAPI (blue). (e) Appearance of the P1 wild-type mouse. (f) The P1 Prtg ${ }^{-1-}$ mouse has the same body size as the wild-type mouse, but has less milk in the stomach (arrow and lower right panel). (g, h) Histochemical staining of acetylcholinesterase activity in the duodenum of P1 Prtg ${ }^{+/+}(\mathbf{g})$ and Prtg ${ }^{-/-}$(h) neonates was examined $(n=11)$. (i, j) Whole-mount neurofilament staining was performed on E10.5 Prtg ${ }^{+/+}$(i) and Prtg ${ }^{-1-}$ (j) embryos. No abnormalities of cranial and spinal nerves were detected in Prtg ${ }^{-/}$embryos $(n=9)$. $(\mathbf{k}-\mathbf{r})$ The morphology of the craniofacial skeletal structures and skull vault of P1 wild-type $(\mathbf{k}, \mathbf{m}, \mathbf{o}, \mathbf{q})$ and Prtg ${ }^{-/-}$ $(\mathbf{l}, \mathbf{n}, \mathbf{p}, \mathbf{r})$ mice as revealed by Alcian blue and/or Alizarin red staining. (k, I) Dorsal views of the palatal bones after the skull is removed show the disappearance of the nasal septum (black dotted outline) and an aperture in basisphenoid bone (arrow) in the $\mathrm{Prtg}^{-/-}$mice. ( $\left.\mathbf{m}, \mathbf{n}\right)$ Coronal sections of the palatine display a thinner palatal bone (arrow) in the Prtg ${ }^{-1-}$ mice. (o, p) Branches (arrow) of ala temporalis (black dotted outline) become shorter or disappear in Prtg ${ }^{-1-}$ mice. (q, r) Lateral views of the skull vault show that mineralization of the parietal bone (yellow dotted outline) and the supraoccipital bone (red dotted outline) is incomplete in the Prtg ${ }^{-/-}$mice. (s) A schematic presentation of the craniofacial defects in Prtg ${ }^{-1-}$ mice is shown in the left. Defective bones (red) and cartilages (blue) are marked. Cell lineage and penetrance of the craniofacial defects observed in Prtg $^{-1-}$ mice, and numbers of mice analyzed are indicated in the right 
of the E13.5 homozygous embryos (Figures 2c and d, $n=7$ for each genome type). These results suggest that fewer R-CNCCs are present in Prtg ${ }^{-/}$- mutants. Notably, there is no defect in the X-gal-staining patterns of the dorsal root ganglia that develop from TNCCs in homozygous embryos.
To confirm that there are losses of R-CNCCs in the absence of Prtg protein, we analyzed expression patterns in E9-E10 embryos of several NCC markers, which are also critical for the development of craniofacial structures by whole-mount in situ hybridization. In wild-type embryos, the expression of

a Targeting
Vector

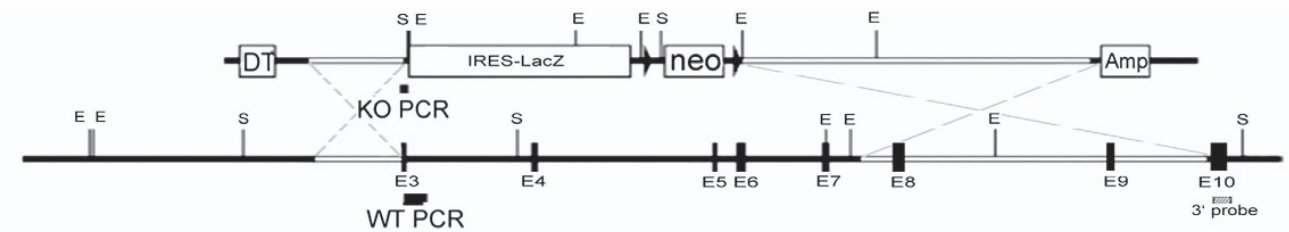

Mutant w/o Neo Allele

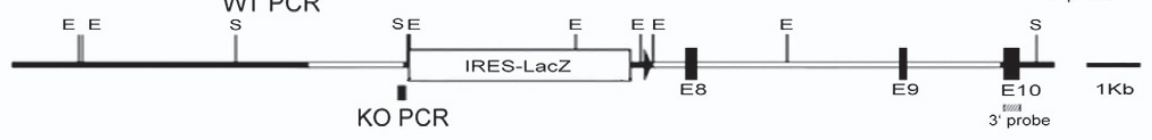

b

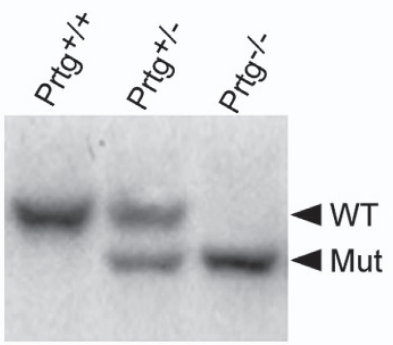

$e^{c} e^{x^{x}} e^{x^{x}} e^{x^{\prime}}$

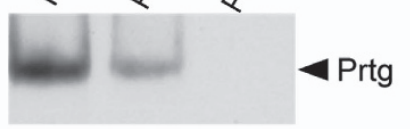

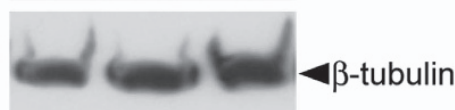
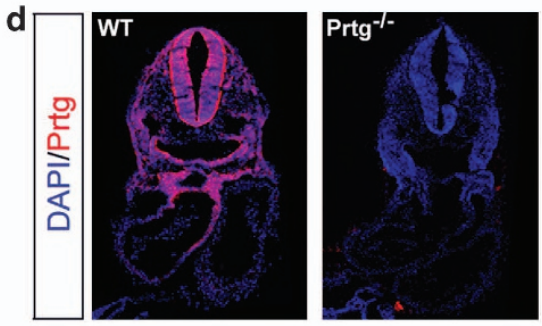
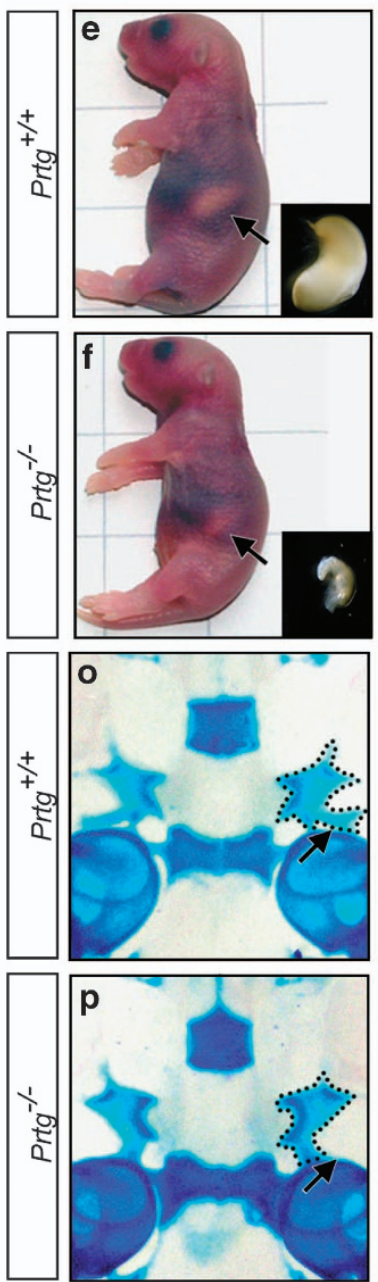
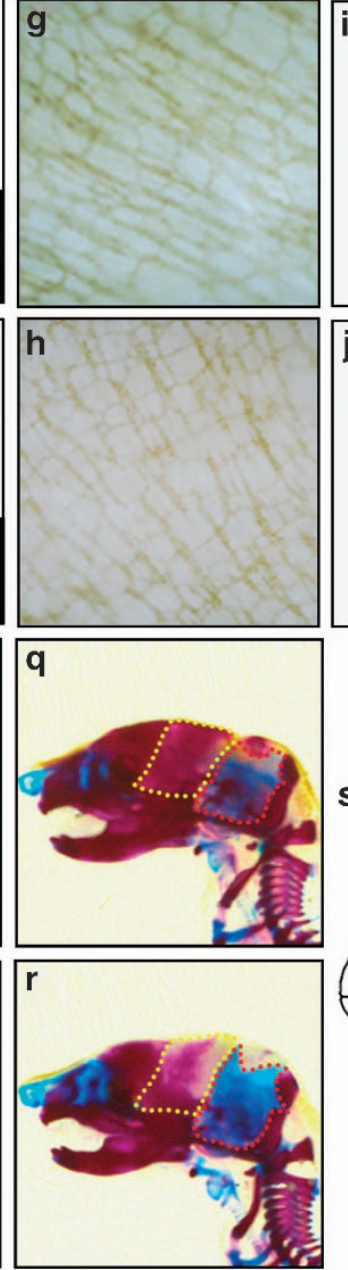
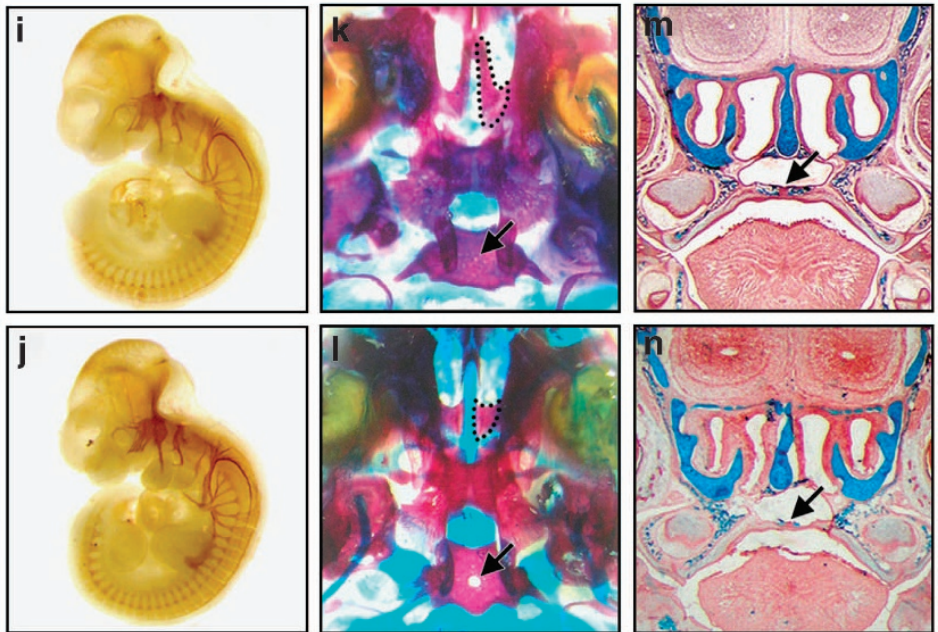

S
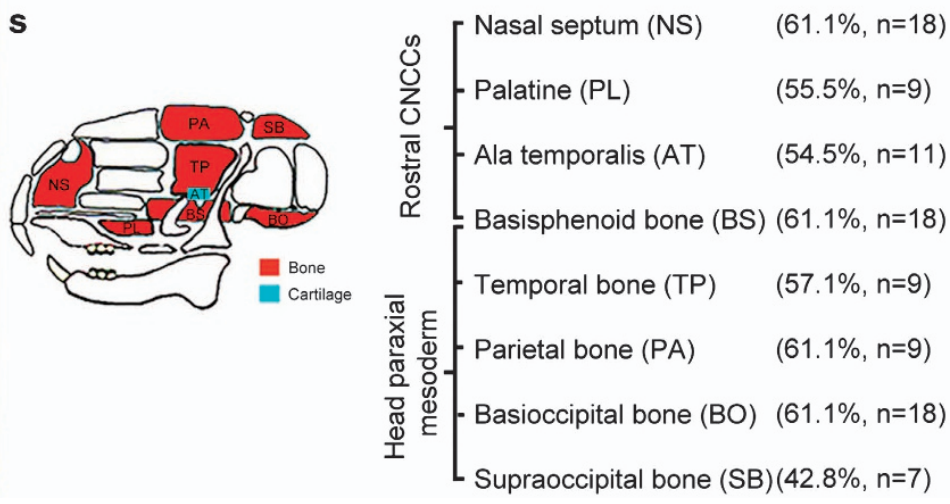


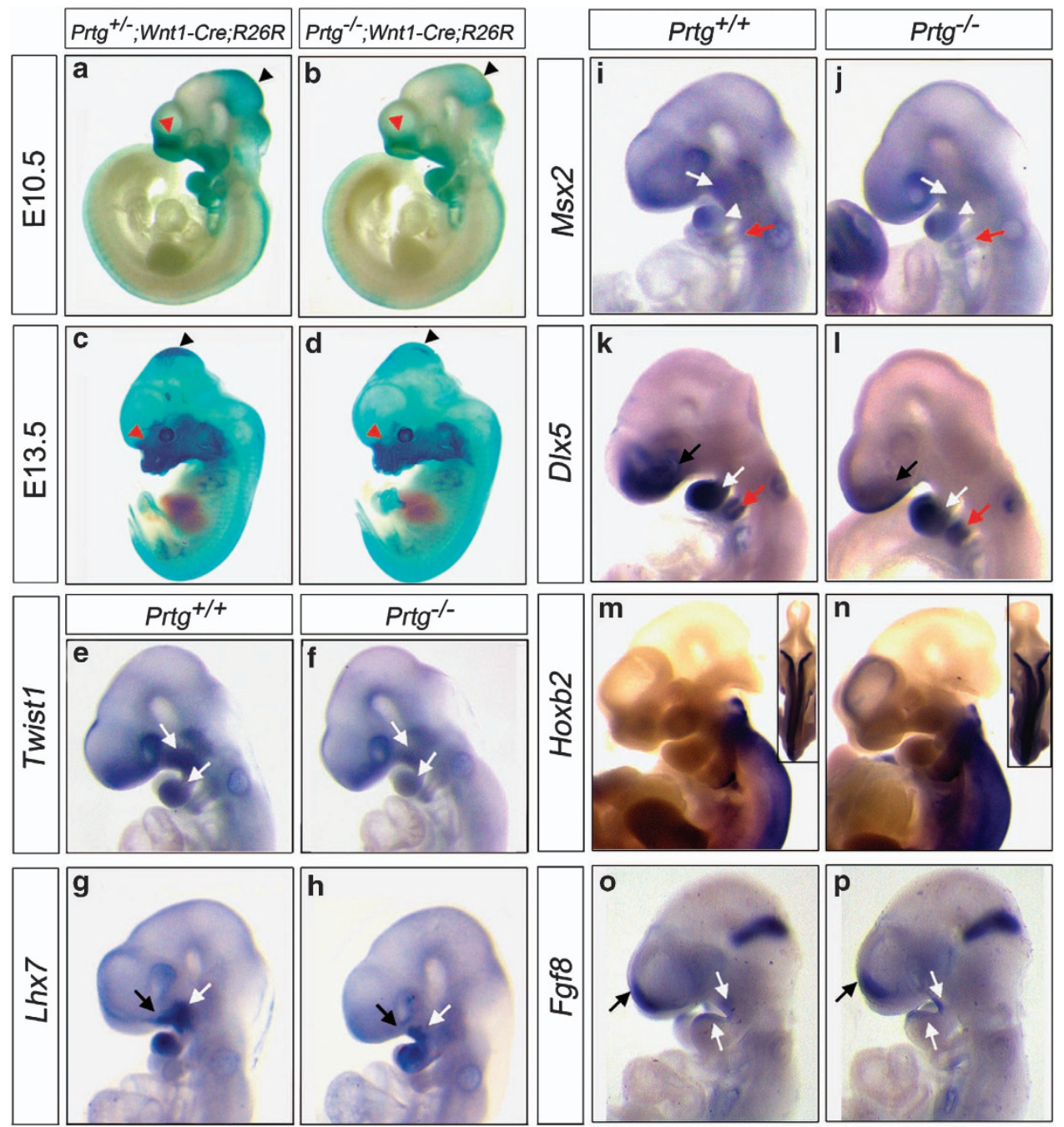

Figure 2 Loss of R-CNCCs in Prtg ${ }^{-1-}$ embryos. (a-d) Embryos of Prtg ${ }^{+/-}$;Wnt1-Cre;R26R and Prtg ${ }^{-1-}$;Wnt1-Cre;R26R were subjected to X-gal lineage tracing analysis. (a, b) E10.5 ( $n=6)$; (c, d) E13.5 $(n=7)$. Fewer R-CNCCs are detected in dorsal midbrain (black arrowhead) and frontonasal primordium (red arrowhead) of Prtg ${ }^{-1-}$;Wnt1-Cre;R26R embryos than in heterozygous embryos. (e-n) In situ hybridization of the indicated genes was performed in E9.5 wild-type and Prtg ${ }^{-/-}$ embryos. (e, f) Expression of Twist 1 in the maxilla and mandible of BA1 (white arrows) is reduced in Prtg ${ }^{-/-}$mice ( $n=8$ for both genome types). (g-h) Expression of Lhx7 is reduced in the frontonasal primordium (black arrows) and maxilla (white arrows) in Prtg ${ }^{-/}$mice $(n=8)$. (i, j) In Prtg ${ }^{-/-}$mice, expression of Msx2 in the maxilla disappears (white arrows). Weaker expression of Msx2 is detected in the mandible (white arrowheads) and there is no change in the BA2 and BA3 (red arrows) ( $n=9$ ). (k, I) DIx5 is slightly reduced in the frontonasal primordium (black arrows) and mandible (white arrows). No difference of DIx5 expression in the BA2 and BA3 (red arrows) between the wild-type and Prtg ${ }^{-1-}$ embryos is detected $(n=8)$. ( $\left.\mathbf{m}, \mathbf{n}\right)$ Expression of Hoxb2 in E10 embryos was analyzed. Insets are dorsal views of the embryos $(n=4)$. $(\mathbf{o}, \mathbf{p})$ Expression of Fgf8 in E9.5 embryos was analyzed. Expression of Fgf8 in the anterior neural ridge (black arrows) and BA1 epithelium (white arrows) is the same between wild-type and mutant embryos $(n=8)$

Twist1 is detected in the maxilla and mandible of BA1. A drastic decrease in Twist1 expression in BA1 is detected in Prtg $^{-/-}$mutants (Figure 2f). Diminished $L h x 7$ in the frontonasal process and the maxilla of BA1 is also observed in $\mathrm{Prtg}^{-1-}$ mutants (arrows in Figure 2h). To examine whether C-CNCCs are defective in $\mathrm{Prtg}^{-/-}$mutant embryos, we analyzed expression of Msx2, a marker for NCCs derived from posterior midbrain to rhombencephalon NC. ${ }^{20}$ Although a decrease in Msx2 expression is detected in the maxilla and mandible of $\mathrm{Prtg}^{-/-}$mutant embryos at E9.5 (white arrows in Figure 2j), expression of $M s \times 2$ in BA2 and BA3 is the same between wild-type and $\mathrm{Prtg}^{-/-}$mice (red arrows in Figures $2 \mathrm{i}$ and j). Analysis of $D / x 5$ expression also indicates that the development of BA2 and BA3 is normal in the $\mathrm{Prtg}^{-/-}$mutants (red arrow in Figure 2l). To further validate that the effects of Prtg activity are restricted to R-CNCCs, we analyzed the expression of Hoxb2, a known marker that defines the identities of NC for C-CNCCs and TNCCs. ${ }^{21}$ The anterior boundary and the level of Hoxb2 expression in $\mathrm{Prtg}^{-1-}$ mutant embryos are the same as in wild-type embryos (Figures $2 \mathrm{~m}$ and $\mathrm{n}$ ), supporting that loss of Prtg does not affect the development of C-CNCCs and TNCCs. Similarly, loss of Prtg activity does not alter the expression of Fgf8, an important growth factor for $\mathrm{CNCCs}^{22}$ in anterior neural ridge and BA1 epithelium (arrows in Figures 20 and $p$ ). 

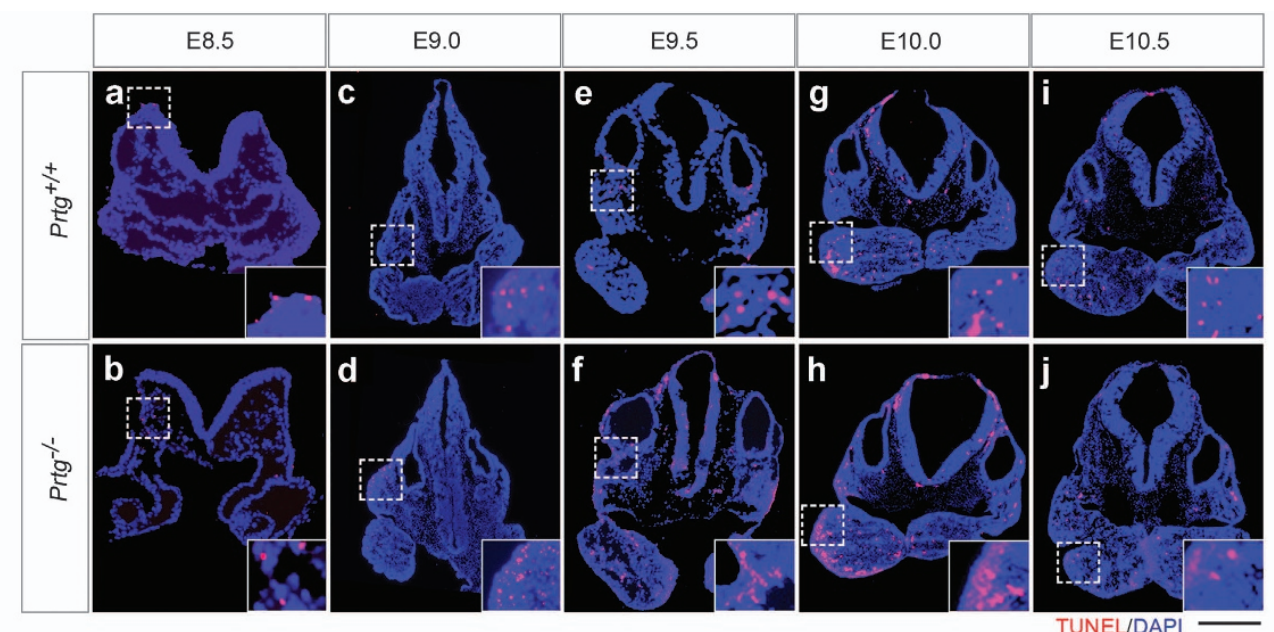

k

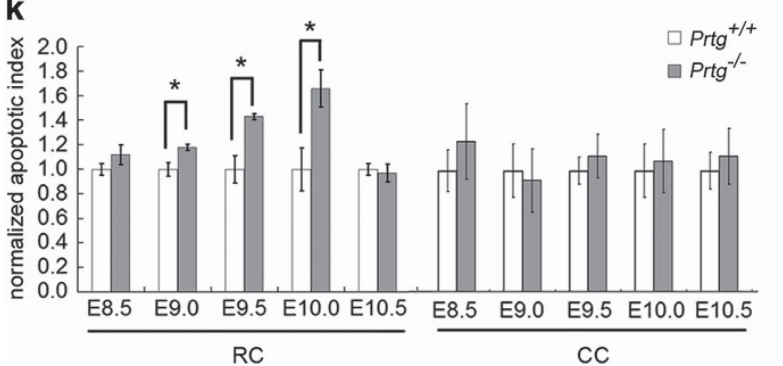

I

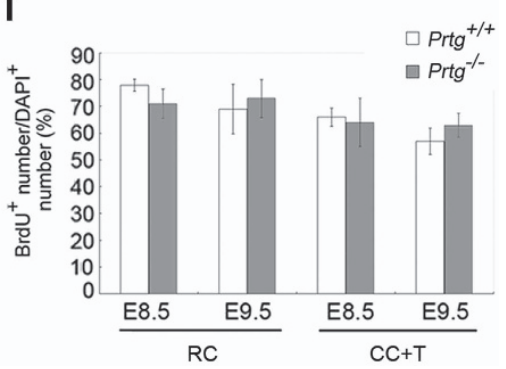

Figure 3 Increased apoptosis in the rostral cephalic region in $\operatorname{Prtg}^{-/-}$embryos. Transverse $12-\mu$ m sections of $\operatorname{Prtg}^{+/+}(\mathbf{a}, \mathbf{c}, \mathbf{e}, \mathbf{g}, \mathbf{i})$ and $P r t g^{-/-}$embryos (b, d, f, h, j) were subjected to TUNEL analysis. (a, b) E8.5; (c, d) E9.0; (e, f) E9.5; (g, h) E10.0 and (i, j) E10.5. Higher magnifications of white boxes are shown in lower right corners. Scale bar, $300 \mu \mathrm{m}$ for (a) and (b); $500 \mu \mathrm{m}$ for (c-f); $600 \mu \mathrm{m}$ for $(\mathbf{g}, \mathbf{h})$ and $800 \mu \mathrm{m}$ for (i, j). (k) Quantification of TUNEL-positive cells shown in (a)-(j). All $12-\mu \mathrm{m} \mathrm{sections} \mathrm{from}$ the E8.5 embryos and every other section from the E9.0-E10.5 embryos were subjected to TUNEL assay. Numbers of TUNEL-positive cells were counted and normalized against the DAPI intensities. Data are further normalized against those of Prtg ${ }^{+/}$embryos and shown as the mean \pm S.E.M. $\left(n=4\right.$; ${ }^{*} P<0.05$, by Student's t-test). RC: rostral cephalic; CC: caudal cephalic. (I) Proliferation analysis. Prtg ${ }^{+/-}$and Prtg $^{-\prime-}$ embryos at E8.5 or E9.5 were harvested after 6-h BrdU labeling. Detection of $\mathrm{BrdU}$ in $\mathrm{RC}$ and $\mathrm{CC} /$ trunk $\left(\mathrm{CC}+\mathrm{T}\right.$ ) regions was performed on $20-\mu \mathrm{m}$ transverse sections. Five sections of each region were randomly selected and numbers of $\mathrm{BrdU}^{+}$and $\mathrm{DAPI}^{+}$cells were counted. The results are shown as the mean \pm S.E.M. $(n=4)$

Prtg is involved in the survival but not proliferation of rostral CNCCs. Fewer R-CNCCs present in Prtg ${ }^{-/-}$ embryos could be due to cell death and/or decreased cell proliferation. To discriminate these possibilities, we conducted a terminal deoxynucleotidyl transferase dUTP nick end labeling (TUNEL) assay to detect whether there is a change in cell survival in $\mathrm{Prtg}^{-/-}$embryos. In the rostral cephalic sections, there are $18 \pm 2.6 \%$ more TUNEL ${ }^{+}$cells in E9.0 Prtg $^{-/-}$embryos, $43 \pm 2.2 \%$ more TUNEL $^{+}$cells in E9.5 $\mathrm{Prtg}^{-/-}$embryos and $66 \pm 15 \%$ more TUNEL ${ }^{+}$cells in E10.0 $\mathrm{Prtg}^{-/-}$embryos compared with $\mathrm{Prtg}^{+/-}$embryos (Figures $3 a-k)$. The increase in $\mathrm{TUNEL}^{+}$cells is spatially restricted to rostral cephalic region and temporally to the period between E9.0 and E10.0. We also performed a 6-h BrdU labeling for cell proliferation analysis in E8.5 and E9.5 $\mathrm{Prtg}^{-/-}$embryos during the time when expression of the Prtg protein is at its highest. There is no decrease of cell proliferation rate in rostral and caudal cephalic/trunk sections at either time points (Figure 3l, and data not shown).

To verify that the increased $\mathrm{TUNEL}^{+}$cells are NCCs, mouse embryos with a Wnt1-Cre;CAT-EGFPflox genetic background are used. Apoptotic cells are revealed by cleaved caspase 3 (cCasp3) staining. Colocalization of cCasp3 $^{+}$and
$\mathrm{EGFP}^{+}$staining indicates that the apoptotic cells are NCCs. At E9.5, there is a $95 \pm 22 \%$ more cCasp3 $^{+} /$EGFP $^{+}$ R-CNCCs in the Prtg ${ }^{-1-}$ mutant embryos compared with heterozygous embryos (Figures $4 a-h$ and $y$ ). No increase of cell death is observed in TNCCs of $\mathrm{Prtg}^{-1-} ;$ Wnt1Cre;CAT-EGFPflox embryos (Figures $4 \mathrm{i}-\mathrm{I}$ and y). Furthermore, apoptosis among non-NCCs (cCasp3 ${ }^{+} /$EGFP ${ }^{-}$cells) along the entire body axis is the same between heterozygous and homozygous embryos (Figure 4y). These results reveal that the increase in apoptotic cells observed in the rostral cephalic region of the Prtg ${ }^{-/-}$embryos during E9-E10, as shown in Figure 3, are likely to involve R-CNCCs. Note that no increase of apoptotic cells are observed in dorsal neural tube (Figure 3b), suggesting that Prtg dose not affect delamination of CNCCs from the neural tube.

As a part of craniofacial skeletal defects exhibited in P1 $\mathrm{Prtg}^{-/-}$mutants is derived from the head paraxial mesoderm lineage, we conducted TUNEL experiments using Mesp1-Cre;CAT-EGFPflox mice ${ }^{18}$ to examine effects of Prtg protein on mesoderm derivatives. It was found that few apoptotic cells are paraxial mesoderm-derived cells in rostral cephalic region (white arrows in Figures $4 \mathrm{~m}-\mathrm{t}$ and $\mathrm{z}$ ) and trunk region (Figures $4 \mathrm{u}-\mathrm{x}$ and $\mathrm{z}$ ) of either $\mathrm{E} 10 \mathrm{Prtg}^{+/-}$; 


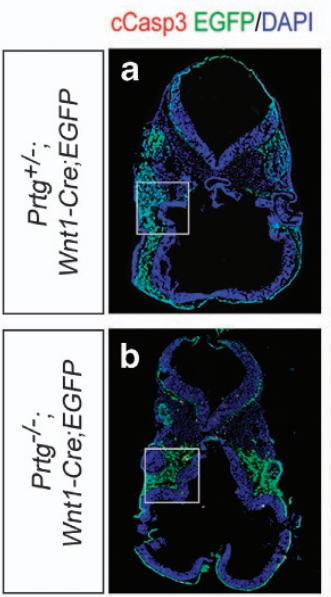

TUNEL EGEP DAPI

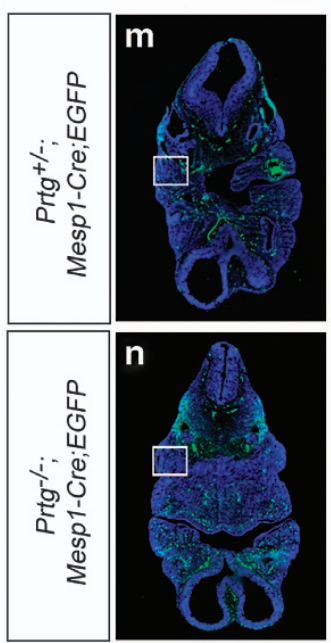

cCasp3
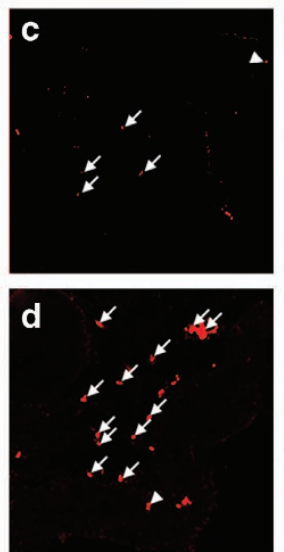

TUNEL
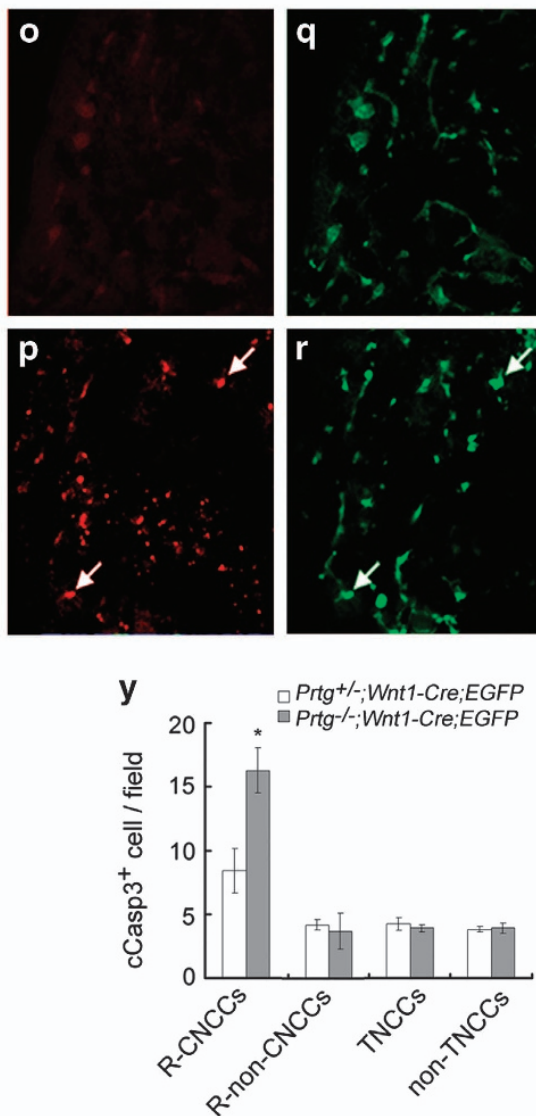

EGFP

EGFP
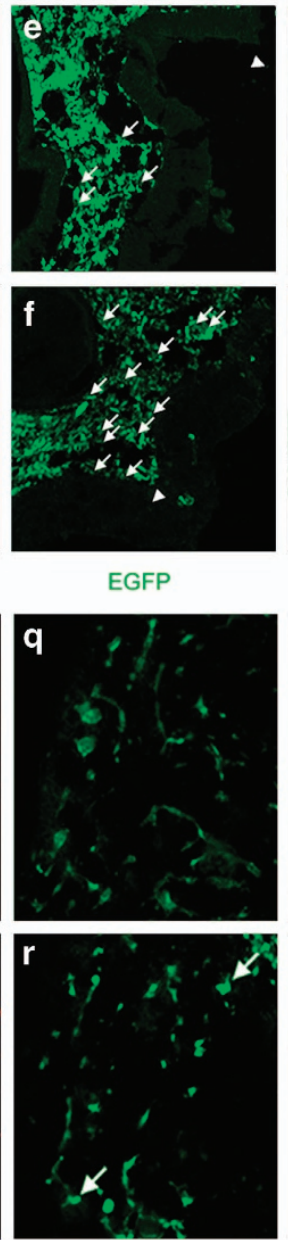

Z
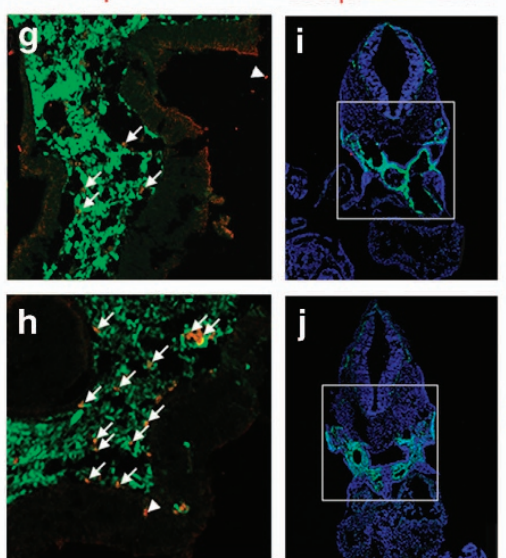

TUNEL/EGFP
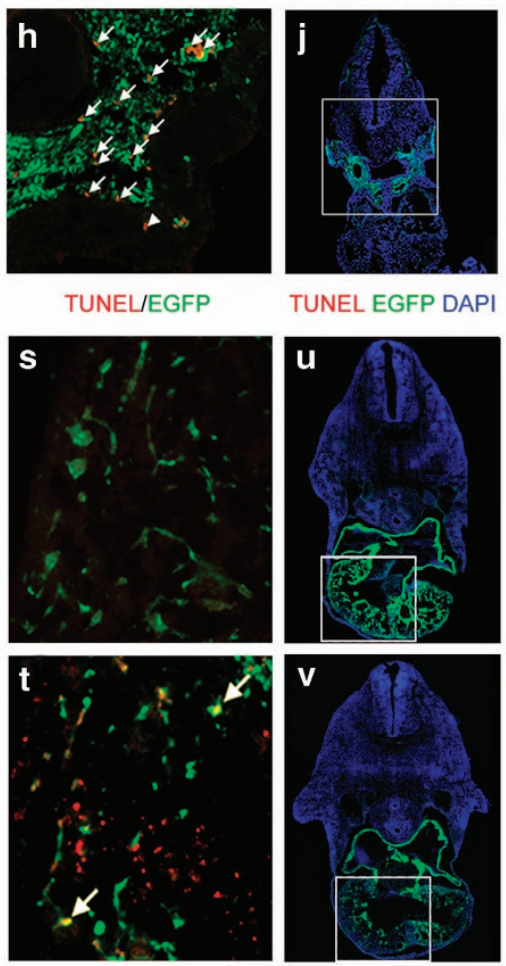

TUNEL EGFP DAPI
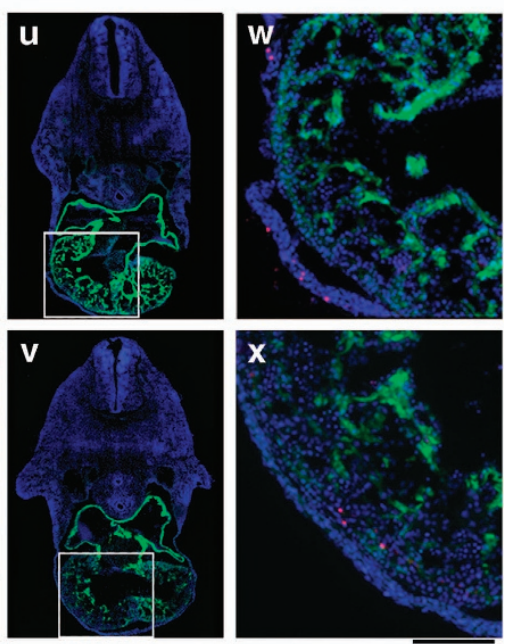

$\mathbf{Z} \quad \mathrm{Prtg}^{+/-; M e s p 1-C r e ; E G F P}$

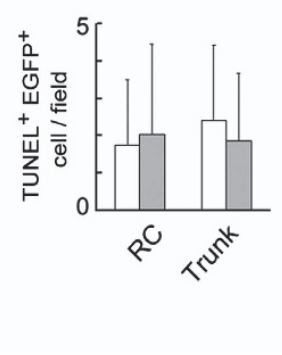

Figure 4 Increase of apoptotic R-CNCCs in E9.5 embryos. (a-I) Transverse sections of E9.5 Prtg ${ }^{+/-}$;Wnt1-Cre;CAT-EGFPflox and Prtg ${ }^{-/-}$; Wnt1-Cre; CAT-EGFPflox embryos were labeled with the antibody against cCasp3. (a-h) At the rostral cephalic level. cCasp3 ${ }^{+} /$EGFP $^{+}$cells are marked with white arrows and cCasp3 $^{+} /$EGFP ${ }^{-}$cells are marked with white arrowheads. (c, e, $\left.\mathbf{g}\right)$ and $(\mathbf{d}, \mathbf{f}, \mathbf{h})$ are higher magnifications of the white boxes in (a) and (b). (i-I) At the trunk level. (k) and (I) are higher magnifications of the white boxes in (i) and (j). (m-x) Transverse sections of E10 Prtg $^{+/-}$;Mesp1-Cre;CAT-EGFPflox and Prtg ${ }^{-/-}$;Mesp1-Cre;CAT-EGFPflox embryos were subjected to TUNEL assay. ( $\mathbf{m}-\mathbf{t})$ At the rostral cephalic level. ( $\mathbf{u}-\mathbf{x})$ At the trunk level. White arrows mark TUNEL ${ }^{+} / \mathrm{EGFP}^{+}$cells. $(\mathbf{o}, \mathbf{q}, \mathbf{s})$ and $(\mathbf{p}, \mathbf{r}, \mathbf{t})$ are higher magnifications of the white boxes in $(\mathbf{m})$ and $(\mathbf{n})$. (w) and $(\mathbf{x})$ are higher magnifications of the white boxes in $(\mathbf{u})$ and $(\mathbf{v})$. Scale bar, $600 \mu \mathrm{m}$ for $(\mathbf{a}, \mathbf{b})$, $(\mathbf{i}, \mathbf{j}, \mathbf{m}, \mathbf{n}, \mathbf{u}, \mathbf{v}) ; 125 \mu \mathrm{m}$ for $\mathrm{C}-\mathrm{H} ; 250 \mu \mathrm{m}$ for (k, l); $100 \mu \mathrm{m}$ for (o-t) and (w, x). (y) Quantification of the apoptotic cells in Prtg ${ }^{+/-}$;Wnt1-Cre;CAT-EGFPflox and Prtg ${ }^{-/-}$; Wnt1-Cre;CAT-EGFPflox embryos at levels of rostral cephalic and trunk regions. All sections were examined for EGFP and cCasp3 staining. The numbers of the cCasp3 ${ }^{+}$ cells per field were counted. The results are shown as the mean \pm S.E.M. $\left(n=4 ;{ }^{*} P<0.05\right.$, by Student's $t$-test). R-non-CNCCs: rostral non-cephalic NCCs; non-TNCCs: trunk non-NCCs. (z) TUNEL ${ }^{+} /$EGFP $^{+}$cells in Prtg ${ }^{+/-}$;Mesp1-Cre;CAT-EGFPflox and Prtg $^{-1-}$;Mesp1-Cre;CAT-EGFPflox embryos were quantified and shown as the mean \pm S.E.M. $(n=4)$. RC: rostral cephalic level 
a
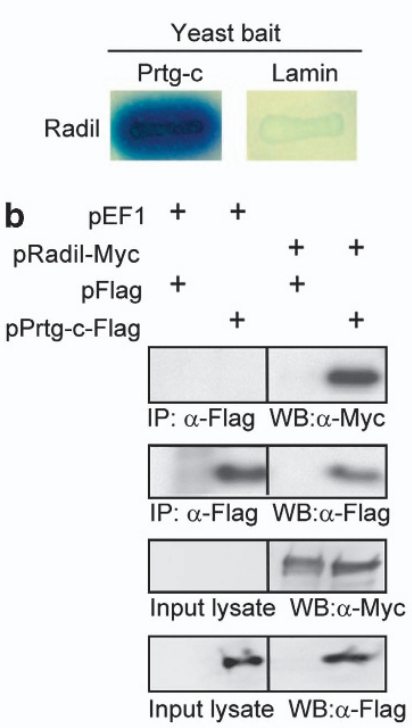

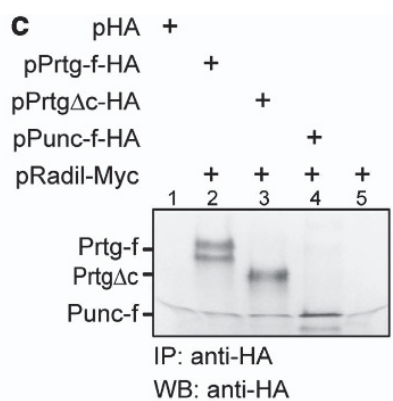

WB: anti-HA
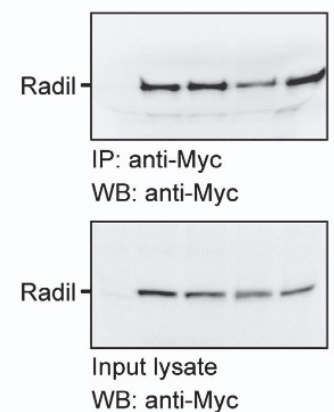

$+$

$+$

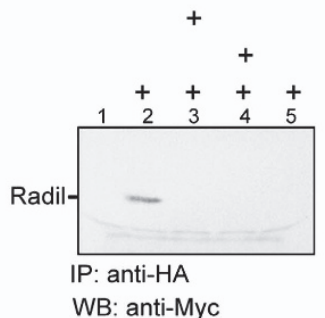

Prtg-f-

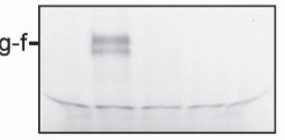

IP: anti-Myc

WB: anti-HA

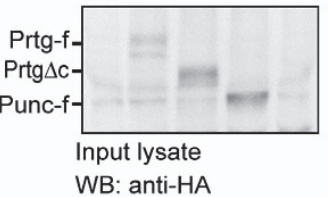

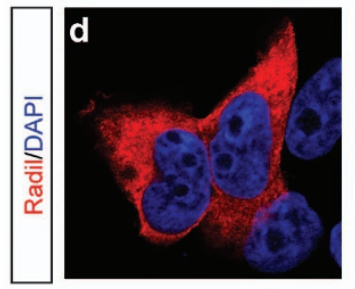
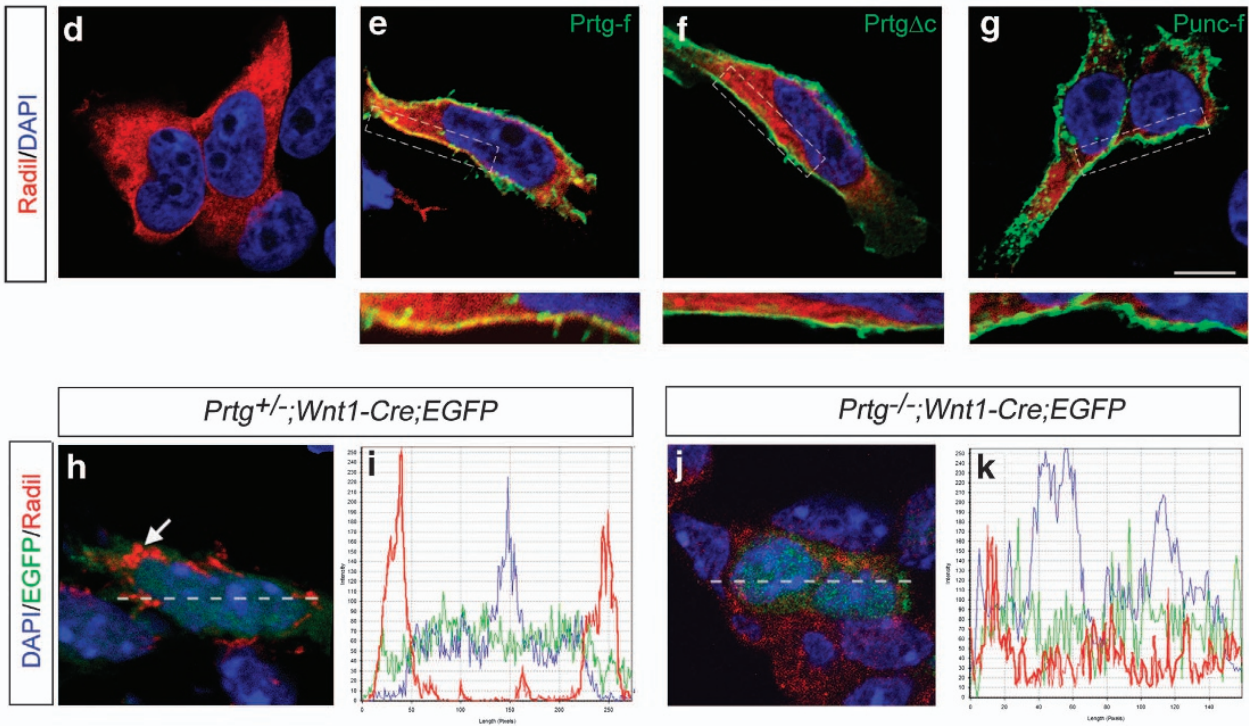

Figure 5 Prtg interacts with Radil. (a) Interaction between Radil and the cytoplsmic domain of Prtg (Prtg-c) or lamin is displayed as $\beta$-galactosidase activity in the yeast two-hybrid assay. (b) HEK293T cells were transfected with indicated plasmids. Cell lysates were immunoprecipitated with rabbit anti-Flag antibodies and subjected to western blot analysis with an anti-Myc or anti-Flag monoclonal antibody. (c) HEK293T cells were transfected with various plasmids. Cell lysates were immunoprecipitated with rabbit anti-HA antibodies (top panels) or rabbit anti-Myc antibodies (middle panels) and subjected to western blot analysis with the anti-Myc or anti-HA monoclonal antibody. (d-g) Myc-tagged Radil was cotransfected with indicated plasmids (all HA-tagged) into HEK293T cells. The subcellular localizations of the overexpressed proteins were labeled with mouse anti-Myc antibody or rabbit anti-HA antiserum and visualized using a confocal microscope. Images shown are representatives of 20 cells analyzed in at least three independent experiments. Lower panels are higher magnifications of the white boxes. Scale bar, $20 \mu \mathrm{m}$. (h, j) Confocal images of Radil (red) expressed in E9.0 R-CNCCs (green) from Prtg ${ }^{+/-}$;Wnt1-Cre;CAT-EGFPflox and Prtg ${ }^{-1-}$; Wnt1-Cre;CAT-EGFPflox embryos. Nuclei are labeled with DAPI (blue). (i, k) Relative fluorescence intensity plots of Radil, DAPI and EGFP along the dotted line shown in (h) and (j)

Mesp1-Cre;CAT-EGFP flox or Prtg ${ }^{-1-}$;Mesp1-Cre;CAT$E G F P^{f l o x}$ embryos. Furthermore, the earliest time point that defective alkaline phosphatase activity, an early marker of osteogenesis, ${ }^{23}$ can be detected in parietal bone is at E15.5 (data not shown). As the defect occurs long after Prtg ceases to be expressed at E10, we reason that it is a consequential effect due to the loss of R-CNCCs.
Prtg protein interacts with Radil. We used the Prtg cytoplasmic domain (Prtg-c) as a bait to search molecules that mediate signaling of Prtg protein in a yeast two-hybrid assay. Among $1.5 \times 10^{6}$ independent clones, 58 DNA fragments were found to interact with Prtg-c. One of these, Radil, shows the strongest interaction with Prtg-c (Figure 5a). As the knockdown of Radil, a Rap1 GTPase interactor, 
interrupts migration of NCCs and results in their apoptosis in zebrafish, ${ }^{24}$ we thus focused on Radil as a putative Prtg downstream binding partner. Immunoprecipitation was performed using HEK293T cell lysates containing overexpressed Flag-tagged Prtg-c and Myc-tagged Radil. The anti-Flag immune complex was then subjected to western blotting. Radil is co-precipitated with Prtg-c (Figure 5b). Moreover, Radil interacts with Prtg-f but not with full-length Punc (Punc-f) (Figure 5c). The extracellular domain of Punc has the highest identity $(43.8 \%)$ with that of Prtg. ${ }^{25}$ The interaction between Prtg and Radil is mediated through the cytoplasmic domain of Prtg, as cytosolic domain-deleted Prtg $(\operatorname{Prtg} \Delta \mathrm{c})$ cannot associate with Radil (Figure 5c, lane 3).

We also analyzed interaction between Prtg and Radil at the cellular level. When overexpressed alone, Radil is localized in a cytoplasmic pool in HEK293T cells (Figure 5d and Ahmed et $a l^{26}$ ). Overexpression of Prtg-f, but not Prtg $\Delta$ c nor Punc-f, leads to the translocation of Radil to the plasma membrane where it colocalizes with Prtg-f (Figures 5e-g). In addition, when sections of E9.0 Prtg $^{+/-} ;$Wnt1-Cre;CAT-EGFPflox embryos are examined with antibody against Radil, Radil is clustered as punctate particles concentrated along cell-cell junctions in R-CNCCs (Figures $5 \mathrm{~h}$ and i); however, Radil is somewhat evenly distributed in Prtg-null R-CNCCs (Figures 5j and k), further supporting that Radil is recruited to plasma membrane by Prtg.

ERdj3/Prtg/Radil signaling promotes cell migration by inducing cell surface expression of the high-affinity $\alpha 5 \beta 1$-integrin. As Radil was shown to control migration of NCCs in zebrafish, ${ }^{24}$ we examined whether Prtg facilitates cell migration by recruiting Radil in the transwell migration assay using cultured AD293 cells. Ectopic expression of Radil or Prtg promotes $39 \pm 5 \%$ and $45 \pm 7 \%$ more cell migration, respectively (Figure $6 a$, bars 2 and 3 ). Overexpression of Radil and Prtg together in AD293 cells produces a synergistic effect that results in $107 \pm 13 \%$ increase in cell migration (Figure 6a, bar 4). When conditioned medium (CM) containing ERdj3 (ERdj3-CM) is added to the lower chamber of the transwell, $309 \pm 69 \%$ more cell migration is detected in AD293 cells overexpressing both Prtg and Radil (Figure 6a, bar 10). Effects of ERdj3 and Prtg on AD293 cell motility are completely abolished when Radil is knocked down by RNA interference (Figure 6b, bar 6 versus bar 8).

A recent study shows that Radil regulates adhesion of cultured cells on fibronectin by activating $\beta 1$-integrin. ${ }^{26}$
Furthermore, knockout of $\alpha 5$-integrin triggers apoptosis of CNCCs. ${ }^{13}$ We thus utilized cell cytometry to examine whether increased expression of high-affinity $\beta 1$ - and $\alpha 5$-integrin subunits on the cell surface is the underlying mechanism responsible for cell mobility induced by ERdj3/Prtg/Radil signaling. Overexpression of either Prtg or Radil increases presentation of high-affinity $\beta 1$ - and $\alpha 5$-integrin subunits on the plasma membrane (Figures $6 c-f$ ). An addition of ERdj3-CM to AD293 cells overexpressing both Prtg and Radil increases cell surface expression of high-affinity $\beta 1$-integrin and $\alpha 5$-integrin to about three times of the control level (Figures $6 \mathrm{~d}$ and $\mathrm{f}$, bar 8 versus bar 1 ). Note that the extent of increased expression of the activated $\beta 1$ - and $\alpha 5$-integrin subunits induced by various treatments of ERdj3, Prtg and Radil match well to the levels of cell motility induced by these treatments. We further demonstrated that overexpressed Prtg is able to co-precipitate endogenous $\beta 1$-integrin in AD293 cells in an immunoprecipitation assay (Figure 6g).

Expression of the high-affinity $\alpha 5 \beta 1$-integrin decreases in Prtg-null R-CNCCs. We further interrogate levels of high-affinity $\alpha 5 \beta 1$-integrins on R-CNCC cell membrane in Prtg $^{-1-}$;Wnt1-Cre;CAT-EGFPflox mutant embryos by immunofluorescence staining. About $35 \%$ less of immunofluorescence intensity of the activated $\beta 1$-integrin subunit are detected in E9.0 Prtg-null R-CNCCs and rostral non-CNCCs; however, no change of the activated $\beta 1$-integrin subunit expression is detected in Prtg-deficient TNCCs and non-TNCCs (Figures 7a-h, q). Expression of the activated $\alpha 5$-integrin subunit in E9.0 R-CNCCs, but not rostral non-CNCCs, also decreases $20 \%$ in the absence of Prtg protein (Figures 7i-p and q). Note that amounts of total $\beta 1$ - and $\alpha 5$-integrin subunits do not change in $\mathrm{Prtg}^{-/-}$ mutant embryos (Figure 7r). To confirm there are fewer highaffinity $\alpha 5 \beta 1$-integrins in Prtg-null R-CNCCs, we examined their cell mobility using the in vitro transwell assay. When dissociated cells isolated from E9.0 embryos were put to test, there were $45 \%$ fewer Prtg-null R-CNCCs migrating through the membrane than Prtg heterozygous R-CNCCs. In contrast, only $22 \%$ fewer Prtg-null rostral non-CNCCs migrate through the membrane than the Prtg heterozygous rostral non-CNCCs (Figure 7s). No difference in migration ability is detected in Prtg-null TNCCs and non-TNCCs. These results suggest that decreased expression of both high-affinity $\alpha 5-$ and $\beta 1$ integrin subunits might exacerbate the deficiency of integrin activity in Prtg-null R-CNCCs.

\footnotetext{
Figure 6 ERdj3/Prtg/Radil signaling activates $\beta 1$ - and $\alpha 5$-integrin in AD293 cells. (a, b) Quantitative results of the transwell assay. At $48 \mathrm{~h}$ after transfection, AD293 cells transfected with indicated plasmids were placed in the upper chamber. The lower chamber contained control CM or ERdj3-containing CM (ERdj3-CM). All data are normalized to the control vector ( $\mathrm{pEF} 1$ ) and shown as the mean \pm S.E.M. Statistic analysis are made between all samples and the control vector, and between samples connected by lines $\left(n=3 ;{ }^{*} P<0.05\right.$, by Student's $t$-test). (c, e) AD293 cells were transfected with indicated plasmids. At $16 \mathrm{~h}$ after transfection, cells were incubated with CM or ERdj3-CM for another $24 \mathrm{~h}$ before flow cytometry analyses of activated $\beta 1$-integrin (c) or activated $\alpha 5$-integrin (e). The gray area and the white area represent fluorescence distribution of cells treated with a control plasmid (pEF1) and indicated plasmids, respectively. The $\mathrm{Mn}^{2+}$-treated group is used as a full activation control. (d, f) are quantitative data of (c) and (e). All data are normalized to the $\mathrm{Mn}^{2+}$-treated control and shown as the mean \pm S.E.M. $\left(n=3 ;{ }^{*} P<0.05\right.$, by Student's $t$-test). (g) Co-precipitation of activated $\beta 1$-integrin with Prtg. Cell lysates of AD293 cells transfected with indicated plasmids (all Myc-tag) and cultured with/without ERdj3 were immunoprecipitated with anti-Myc antibody. The immunoprecipitates were subjected to western analysis with indicated antibodies. Lower four panels are immunoblots loaded with $20 \%$ of cell lysates used in immunoprecipitation
} 


\section{Discussion}

NCCs are a transient population of cells that undergo epithelial-to-mesenchymal transition along the anteroposterior body axis. Depending on their origins in the neural tube, NCCs migrate and populate in cranial, cardiac, trunk and enteric domains. ${ }^{3}$ In each domain, these cells enter into various tissues and become cell types that match the needs of that particular tissue by interacting with neighboring cells a

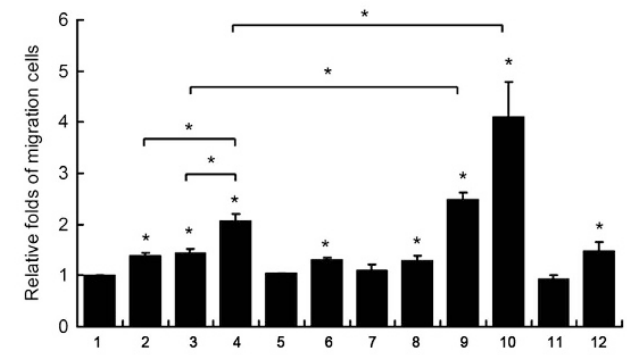

pEF1

pRadil-Myc

pPrtg-f-Myc

pPrtg-c-Myc

$\mathrm{CM}$

ERdj3-CM

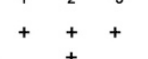

$++$
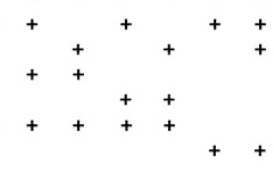

C
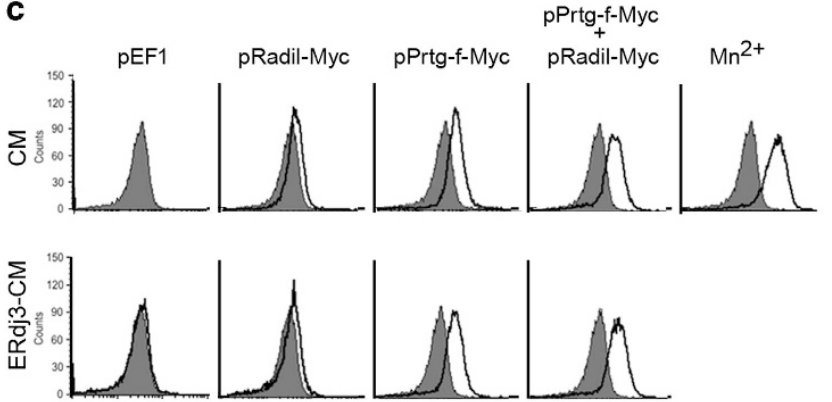

e

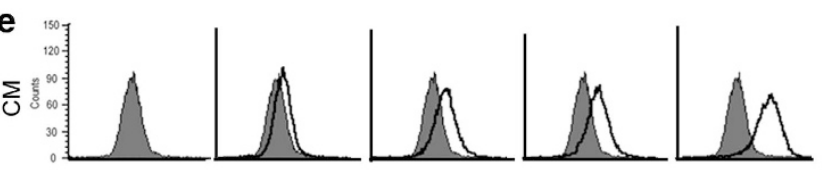

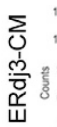

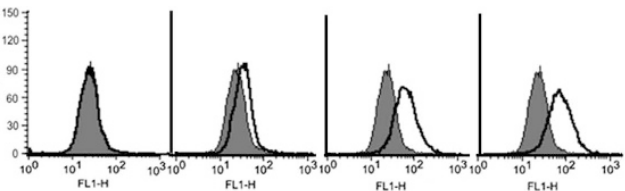

g
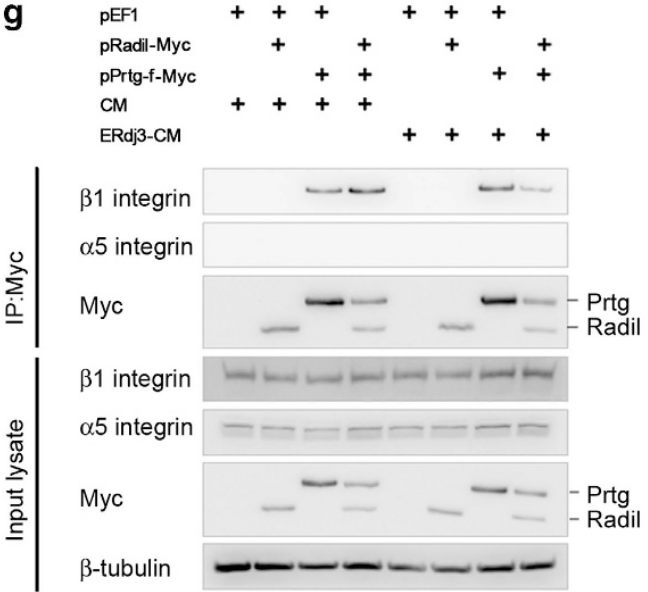
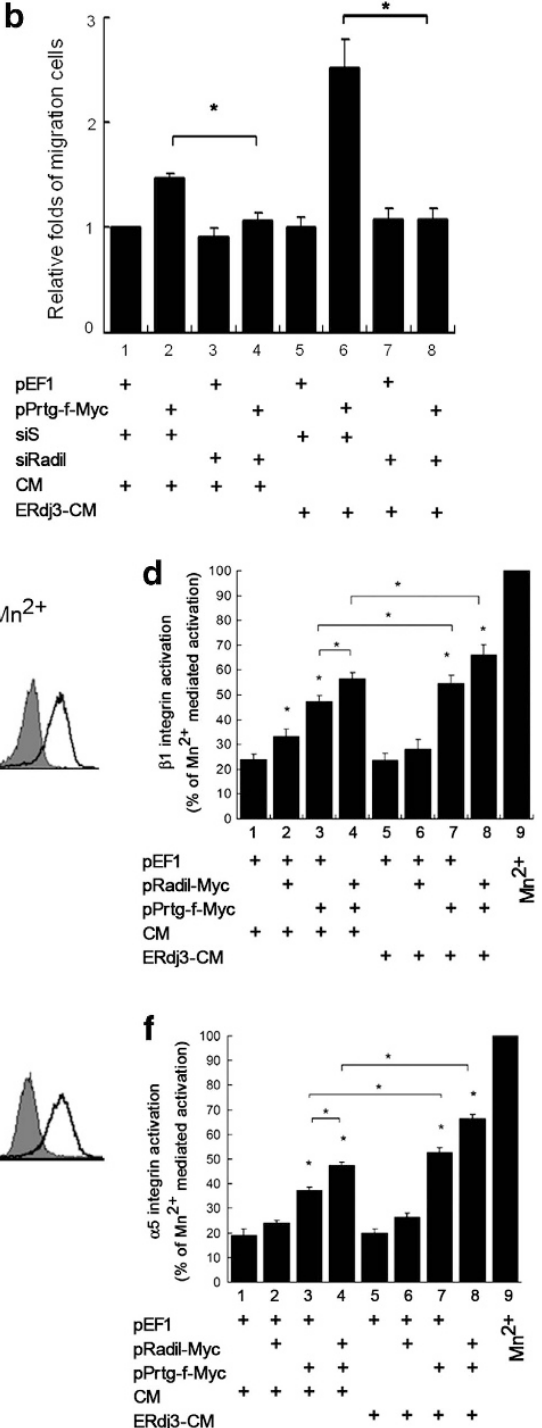
reciprocally. Here we report that an immunoglobulin family member, Prtg, is involved in the survival of R-CNCCs that contribute to the osteogenic and chondrogenic cells in the craniofacial structures. In $\mathrm{Prtg}^{-/-}$embryos, increased cell death is detected in R-CNCCs during E9-E10 (Figure 8a).
Later in development, the loss of these cells delays the development of mesoderm-derived mesenchymal cells. These direct and indirect effects manifest the craniofacial phenotypes that we detect in $\mathrm{Prtg}^{-/-}$mutant mice at birth. We further provide in vitro evidence that Prtg recruits Radil to

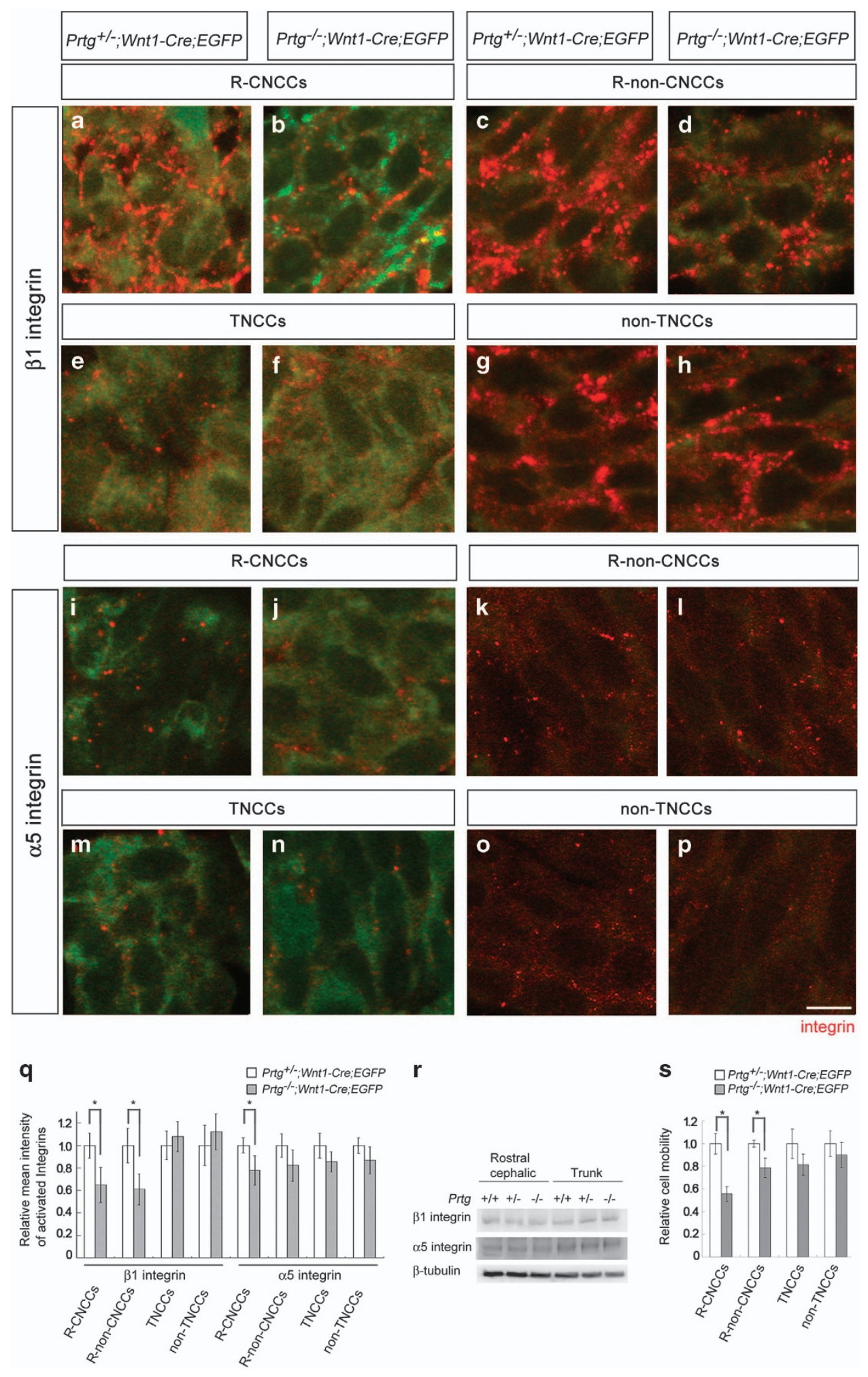


the plasma membrane, and subsequently changes the structure of the $\alpha 5 \beta 1$-integrin to high-affinity conformation, and facilitates cell migration (Figure $8 b$ ). In the absence of Prtg proteins, fewer Radil proteins are translocated to the membrane, and consequently fewer $\alpha 5 \beta 1$-integrins are activated to high-affinity conformation in $\mathrm{Prtg}^{-/-}$embryos; thus, a subset of R-CNCCs undergoes premature apoptosis. As Radil associates with Rap1, and talin is the converging point in the inside-out integrin activation, ${ }^{26-28} \mathrm{ERdj} 3 / \mathrm{Prtg} /$ Radil signaling pathway may also involve Rap1 and talin to activate $\alpha 5 \beta 1$-integrin (Figure $8 \mathrm{~b}$ ).

Signaling involved in the survival of R-CNCCs. Two possible, but not exclusive, scenarios may explain how cell death program is initiated in a subset of Prtg-deficient R-CNCCs as observed in this study. First, it had been shown that the $\alpha 5 \beta 1$-integrin supports survival of cultured cells grown on fibronectin by upregulating Bcl-2 expression. ${ }^{29}$ Signaling molecules, including Shc, FAK, Ras, PI3K and Akt, are required for the increase of $b c /-2$ transcription induced by $\alpha 5 \beta 1$-integrin activity. ${ }^{30}$ It is thus likely that extracellular matrix molecules in $\mathrm{Prtg}^{-/}$embryos cannot transmit survival signals for Prtg-deficient R-CNCCs due to insufficient amounts of the high-affinity $\alpha 5 \beta 1$-integrin on plasma membrane of these cells. Alternatively, the migration defect may be the cause for R-CNCC death. In the absence of Prtg, insufficient exhibition of high-affinity $\alpha 5 \beta 1$-integrin interrupts migration of a subset of R-CNCCs along their migratory pathways toward frontonasal primordium and BA1, thus preventing their access to the local survival factors, such as BMP2, BMP4 and FGF8. 22,31 Results that 45\% fewer Prtg-null R-CNCCs migrate through the transwell membrane (Figure 7s) lend some support to the latter possibility. In addition, Smolen et al. ${ }^{24}$ showed that the blockage of apoptosis is not able to prevent craniofacial defects observed in zebrafish after knocking down Radil, suggesting that effects of Radil are primarily on migration. Owing to many cells migrating at the same time in mouse E8.5-E9.0 a

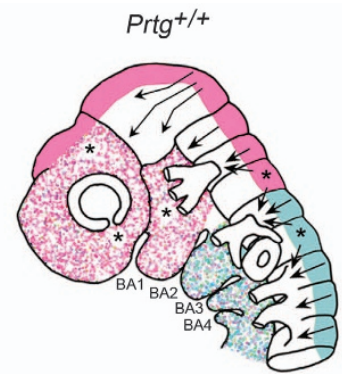

b

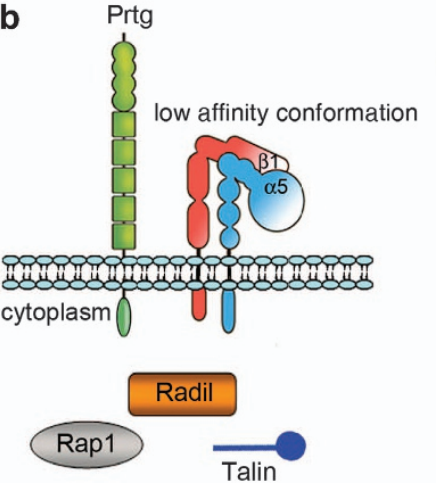

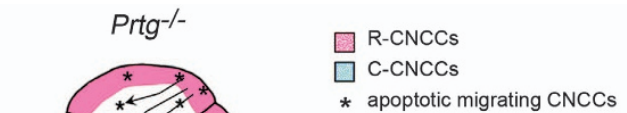

* apoptotic migrating CNCCs 
embryos and only a part of R-CNCCs is affected by Prtg deficiency, we were not able to resolve these two possibilities in this study. Finding a new way to label only a few R-CNCCs in mouse embryos and performing direct comparison of migration rates of R-CNCCs in control and Prtg ${ }^{-/-}$embryos will be needed to solve the issue.

\section{Presence of a redundant gene(s) that substitutes loss} of Prtg. Expression of Prtg protein in mesoderm begins as early as E7 and is present in almost all cells between E8.25 and E9.5, except in the notochord and differentiating cardiac cells. ${ }^{15}$ When levels of Prtg mRNA are perturbed by an RNA interference approach in stage 6 chick embryos, ingression of paraxial mesoderm precursor cells is impaired. ${ }^{17}$ If levels of Prtg mRNA are perturbed at stage 9, precocious neuronal differentiation in the developing chick neural tube occurs. ${ }^{15}$ Furthermore, using a mouse mandible organ culture, Takahashi et al. ${ }^{16}$ showed that knockdown of Prtg mRNA in tooth germ causes an arrest of the tooth development. These results suggest that Prtg may have roles in migration of primitive mesoderm cells, neuronal differentiation and tooth germ formation. Thus, it is unexpected that no embryonic lethality, no abnormality in the nervous system and no defects in dental tissue could be detected in $\mathrm{Prtg}^{-/-}$mutants. Further studies are required to find out why the discrepancy occurs and to search for the redundant gene compensating the loss of Prtg during development.

\section{Materials and Methods \\ Animals. Adult C57BL/6J mice were obtained from the National Laboratory Animal Center (Taipei, Taiwan, ROC). CAT-EGFPflox mice were described previously. ${ }^{32}$ R26R transgenic mice were kindly provided by Ting-Fen Tsai. Wnt1- Cre mice were purchased from the Jackson Laboratories (Bar Harbor, ME, USA). Mesp1-Cre mice were obtained from RIKEN BioResource Center (Ibaraki, Japan). ${ }^{33}$ All mice were handled according to the university guidelines and experiments were approved by the National Yang-Ming University Animal Care and Use Committee. For the timed pregnancies, mice were set up in the late afternoon and when plugs were detected the next morning, this was designated as E0.5.}

Materials. Expand high-fidelity Taq DNA polymerase, deoxynucleotides, $4^{\prime}, 6^{\prime}$-diamidino-2-phenylindole (DAPI), the in situ Cell Death Detection kit (TUNEL), reagents used in the in situ hybridization were obtained from Roche (Indianapolis, IN, USA). Taq DNA polymerase were purchased from Promega (Madison, WI, USA). The primers used in the PCRs were synthesized by MDBiol (Taipei, Taiwan). All other chemicals, unless otherwise specified, were purchased from Sigma (St. Louis, MO, USA).

Vector construction. The various Prtg plasmids had been constructed previously. ${ }^{15}$ The mouse open reading frames of Punc and Radil were amplified by PCR using primers listed in Supplementary Table S1 and cloned to pEF1/Myc-His. The plasmids containing Dlx5, Fgf8, Lhx7 and Msx2 for in situ hybridization were provided by J Rubenstein (Department of Psychiatry, UCSF, San Francisco, CA, USA), Y-T Yan (Institute of Biomedical Sciences, Academia Sinica, Taipei, Taiwan), V Pachnis (National Institute for Medical Research, Medical Research Council, London, UK) and Y-H Liu (Department of Biochemistry and Molecular Biology, Kenneth R. Norris Cancer Hospital and Institute, Los Angeles, CA, USA), respectively. Other probes were generated by PCR using E9.5 mouse cDNA as template and cloned in pCRII-TOPO (Invitrogen, Grand Island, NY, USA). DNA fragments containing Radil sequences and scramble sequences (Supplementary Table S1) were cloned into pUI4-puro-SIBR to give rise to siRadil and siS. All plasmids were verified by restriction enzyme mapping and/or sequencing.
Antibodies. Mouse anti-Prtg monoclonal antibody (PRTG2, $1 \mu \mathrm{g} / \mathrm{ml}$ ) has been described previously. ${ }^{15}$ Mouse anti- $\beta$-tubulin antibody (E7, $\left.1: 10000\right)$, mouse anti-neurofilament antibody (2H3, 1:900) and anti-Myc antibody (9E10, 1:5000) were obtained from the Developmental Studies Hybridoma Bank (University of lowa, lowa City, IA, USA). Rabbit monoclonal antibody against cCasp3 (5A1E, $1: 400$ ) was purchased from Cell Signaling (Danvers, MA, USA). Mouse anti-Flag M2 monoclonal antibody $(1: 1000)$ and rabbit anti-Flag polyclonal antiserum $(1: 1000)$ were purchased from Sigma. Mouse anti-activated $\alpha 5$-integrin antibody (SNAKA51, $10 \mu \mathrm{g} / \mathrm{ml}$ ) was from Dr. MJ Humphries. Rabbit anti- $\alpha 5$-integrin antibody $(1: 1000)$ was from Chemicon (Billerica, MA, USA). Rat anti- $\beta 1$-integrin antibody (9EG7, $10 \mu \mathrm{g} / \mathrm{ml}$ ) was from BD Bioscience (San Jose, CA, USA). Rabbit anti- $\beta 1$-integrin antibody (ab52971, 1:1000) was from Abcam (Cambridge, MA, USA). Rabbit anti-Radil antibody ( $1: 300)$ was from Abgent (San Diego, CA, USA).

Targeted disruption of the mouse Prtg gene. The targeting vector was linearlized and electroporated into 129/Sv ES cells. G418-resistant ES colonies obtained by homologous recombination were selected by Southern blot hybridization. Two correctly targeted ES cell lines and one Neo pop-out ES cell line were injected into blastocysts and the resultant chimeras bred with C57BL/6J mice. Genotyping was performed by Southern blotting and/or PCR using the primers listed in Supplementary Table S1. Heterozygous F1 mice were backcrossed with C57BL/6J mice and mice after congenic N12 were used in the study.

Histological analysis, X-gal staining and whole-mount in situ hybridization. Embryos were dissected and fixed with $4 \%$ paraformaldehyde at $4{ }^{\circ} \mathrm{C}$ for $20 \mathrm{~min}$ (for $\mathrm{X}$-gal staining), or overnight (for in situ hybridization and histological staining). For tissue sections, embryos were further soaked in $30 \%$ sucrose for overnight and then cryostat sectioned at $12 \mu \mathrm{m}$. For the histology, frozen sections were stained with hematoxylin-eosin using standard procedures. For whole-mount $\mathrm{X}$-gal staining, the embryo were processed for $\beta$-galactosidase activity as described. ${ }^{34}$ The in situ hybridization procedure was performed as described previously. ${ }^{35}$ The protocols of staining with Alizarin red to reveal bone and Alcian blue to reveal cartilage were published previously. ${ }^{36}$

Detection of cell death. Transverse sections of embryos were cut at $12 \mu \mathrm{m}$ and subjected to TUNEL assay and DAPI staining. Alternatively, sections were labeled with antibodies against cCasp3. The numbers of TUNEL ${ }^{+}$and cCasp3 ${ }^{+}$ cells were counted manually.

Yeast two-hybrid analysis. The rat Prtg-c (amino acids 966-1193) was cloned into the vector pBTM-116 as a bait. An E7 mouse embryo cDNA library fused to the GAL4 activation domain (Clontech) was used as the prey library. Other procedures have been described previously. ${ }^{15}$

Cell culture, protein extraction, immunoprecipitation and Western blotting. Previously described procedures were followed for these experiments. ${ }^{15}$

Migration assay. Human AD293 cells were transfected with different plasmids using calcium phosphate method and cultured for 2 days in $10 \% \mathrm{FBS} /$ DMEM at $37{ }^{\circ} \mathrm{C}$ in a $5 \% \mathrm{CO}_{2}$ incubator. Cells were then detached from culture dishes using $1 \mu \mathrm{M}$ EDTA and resuspended in $0.5 \%$ FBS/DMEM medium. A total of $1 \times 10^{5}$ cells was seeded to the migration chamber (Millicell with $8 \mu \mathrm{m}$ pore size; Millipore, Billerica, MA, USA); the lower chambers contained CM collected from pEF1- or pERdj3-transfected HEK293T cells that were cultured in $0.5 \% \mathrm{FBS} /$ DMEM from 24 to $72 \mathrm{~h}$ after transfection. Duration of migration lasted $4 \mathrm{~h}$ and migratory cells were stained with Hoechst 33258 and quantified by counting four random fields.

For detection of primary cell mobility, tissues from rostral cephalic region and trunk region were dissected from E9.0 (15-18 somite stage) embryos and dissociated with collagenase $(0.75 \mathrm{mg} / \mathrm{ml})$ at $37^{\circ} \mathrm{C}$ for $5 \mathrm{~min} .^{37}$ Dissociated cells were filtered through $40 \mu \mathrm{m}$ cell strainers (BD Falcon, San Jose, CA, USA). A total of $3 \times 10^{3}$ cells were seeded to the upper chamber coated with fibronectin. Duration of migration lasted $5 \mathrm{~h}$. EGFP ${ }^{+}$and EGFP ${ }^{-}$cells in the upper chambers and bottom chambers were fixed and stained with DAPI, and quantified under a fluorescence microscope. The ratio of migration is defined as cell numbers of the bottom chambers divided by the total cell numbers in both chambers and normalized to that of control embryos. 
Flow cytometry. AD293 cells were dissociated with trypsin, washed two times with PBS, re-suspended in DMEM containing $0.1 \%$ BSA and $20 \mathrm{mM}$ HEPES, pH 7.4. Cells were then recovered at room temperature for $30 \mathrm{~min}$. Cells were incubated with anti- $\beta 1$-integrin (9EG7) or anti- $\alpha 5$-integrin (SNAKA51) antibody at room temperature for $1 \mathrm{~h}$. For positive control, $2 \mathrm{mM} \mathrm{Mn}^{2+}$ was added when cells were incubated with primary antibodies. Cells were washed three times with PBS and incubated with Alexa-488-conjugated donkey anti-rat IgG or Alexa-488-conjugated donkey anti-mouse IgG (Jackson ImmunoResearch, Baltimore, PA, USA) at room temperature for $45 \mathrm{~min}$. After three washes in PBS, cells were fixed in $4 \%$ paraformaldehyde at room temperature for $15 \mathrm{~min}$ and re-suspended in PBS. Flow cytometry measurement was taken in a FACSCalibur flow cytometer using the CellQuest Pro software (BD Biosciences) for data acquisition and analysis. Integrin activation was expressed as the ratio of the mean of fluorescence to the $\mathrm{Mn}^{2+}$-treated group.

\section{Conflict of Interest}

The authors declare no conflict of interest.

Acknowledgements. We thank LS Kao, L-J Lo, T-W Wang and J-Y Yu for discussion and critical reading of the manuscript, MC Colbert for providing CAT-EGFPflox mice, MJ Humphries for SNAKA51 and the Developmental Studies Hybridoma Bank for providing monoclonal antibodies. This research was supported by National Science Council (NSC95-2320-B-010-059-MY2 and NSC99-2321-B-010016) and the Ministry of Education (Aim for the Top University Plan) to M-J Fann.

\section{Author contributions}

Y-CW, H-CJ, Y-HW and M-JF conceived and designed the experiments. Y-CW, H-CJ, Y-HW, W-CK, Y-LL, S-FL and C-JL conducted experiments. Y-CW and M-JF wrote the manuscript.

1. Farlie PG, McKeown SJ, Newgreen DF. The neural crest: basic biology and clinical relationships in the craniofacial and enteric nervous systems. Birth Defects Res C 2004; 72: 173-189.

2. Trainor PA, Tan SS, Tam PP. Cranial paraxial mesoderm: regionalisation of cell fate and impact on craniofacial development in mouse embryos. Development 1994; 120 2397-2408.

3. Le Douarin NM, Kalcheim C. The Neural Crest. 2nd edn. Cambridge University Press: New York, NY, USA, 1999

4. Minoux M, Rijli FM. Molecular mechanisms of cranial neural crest cell migration and patterning in craniofacial development. Development 2010; 137: 2605-2621.

5. Etchevers HC, Vincent C, Le Douarin NM, Couly GF. The cephalic neural crest provides pericytes and smooth muscle cells to all blood vessels of the face and forebrain. Development 2001; 128: 1059-1068.

6. Le Douarin NM, Creuzet S, Couly G, Dupin E. Neural crest cell plasticity and its limits. Development 2004; 131: 4637-4650.

7. Dupin E, Calloni GW, Le Douarin NM. The cephalic neural crest of amniote vertebrates is composed of a large majority of precursors endowed with neural, melanocytic chondrogenic and osteogenic potentialities. Cell Cycle 2010; 9: 238-249.

8. Trainor PA, Tam PP. Cranial paraxial mesoderm and neural crest cells of the mouse embryo: co-distribution in the craniofacial mesenchyme but distinct segregation in branchial arches. Development 1995; 121: 2569-2582.

9. Bronner-Fraser M. An antibody to a receptor for fibronectin and laminin perturbs cranial neural crest development in vivo. Dev Biol 1986; 117: 528-536.

10. Bronner-Fraser M. Alterations in neural crest migration by a monoclonal antibody that affects cell adhesion. J Cell Biol 1985; 101: 610-617.

11. Testaz S, Delannet M, Duband J-L. Adhesion and migration of avian neural crest cells on fibronectin require the cooperating activities of multiple integrins of the $\beta 1$ and $\beta 3$ families. J Cell Sci 1999; 112: 4715-4728.

12. Alfandari D, Cousin H, Gaultier A, Hoffstrom BG, DeSimone DW. Integrin $\alpha 5 \beta 1$ supports the migration of Xenopus cranial neural crest on fibronectin. Dev Biol 2003; 260 449-464.

13. Goh KL, Yang JT, Hynes RO. Mesoderm defects and cranial neural crest apoptosis in $\alpha 5$ integrin-null embryos. Development 1997; 124: 4309-4319.
14. Strachan LR, Condic ML. Neural crest motility on fibronectin is regulated by integrin activation. Exp Cell Res 2008; 314: 441-452.

15. Wong Y-H, Lu A-C, Wang Y-C, Cheng H-C, Chang C, Chen P-H et al. Protogenin defines a transition stage during embryonic neurogenesis and prevents precocious neuronal differentiation. J Neurosci 2010; 30: 4428-4439

16. Takahashi KF, Kiyoshima T, Kobayashi I, Xie M, Yamaza H, Fujiwara H et al. Protogenin, a new member of the immunoglobulin superfamily, is implicated in the development of the mouse lower first molar. BMC Dev Biol 2010; 10: 115.

17. Ito $\mathrm{K}$, Nakamura $\mathrm{H}$, Watanabe $\mathrm{Y}$. Protogenin mediates cell adhesion for ingression and re-epithelialization of paraxial mesodermal cells. Dev Biol 2011; 351: 13-24.

18. McBratney-Owen B, Iseki S, Bamforth SD, Olsen BR, Morriss-Kay GM. Development and tissue origins of the mammalian cranial base. Dev Biol 2008; 322: 121-132.

19. Jiang X, Rowitch SH, Soriano P, McMahon AP, Sucov HM. Fate of the mammalian cardiac neural crest. Development 2000; 127: 1607-1616.

20. Takahashi K, Nuckolls GH, Takahashi I, Nonaka K, Nagata M, Ikura T et al. Msx2 is a repressor of chondrogenic differentiation in migratory cranial neural crest cells. Dev Dyn 2001; 222: 252-262.

21. Hunt $P$, Gulisano M, Cook M, Sham MH, Faiella A, Wilkinson D et al. A distinct Hox code for the branchial region of the vertebrate head. Nature 1991; 353: 861-864.

22. Trumpp A, Depew MJ, Rubenstein JL, Bishop JM, Martin GR. Cre-mediated gene inactivation demonstrates that FGF8 is required for cell survival and patterning of the first branchial arch. Genes Dev 1999; 13: 3136-3148.

23. Tsai MT, Li WJ, Tuan RS, Chang WH. Modulation of osteogenesis in human mesenchymal stem cells by specific pulsed electromagnetic field stimulation. J Orthop Res 2009; 27: 1169-1174.

24. Smolen GA, Schott BJ, Stewart RA, Diederichs S, Muir B, Provencher HL et al. A Rap GTPase interactor, RADIL, mediates migration of neural crest precursors. Genes Dev 2007; 21: 2131-2136.

25. Vesque C, Anselme I, Couve E, Charnay P, Schneider-Maunoury S. Cloning of vertebrate Protogenin (Prtg) and comparative expression analysis during axis elongation. Dev Dyn 2006; 235: 2836-2844.

26. Ahmed SM, Daulat AM, Meunier A, Angers S. G protein $\beta \gamma$ subunits regulate cell adhesion through Rap1a and its effector Radil. J Biol Chem 2010; 285: 6538-6551.

27. Han J, Lim CJ, Watanabe N, Soriani A, Ratnikov B, Calderwood DA et al. Reconstructiing and deconstructing agonist-induced activation of integin $\alpha$ llb $\beta 3$. Curr Biol 2006; 16: 1796-1806.

28. Tadokoro S, Shattil SJ, Eto K, Tai V, Liddington RC, de Pereda JM et al. Talin binding to integrin ${ }^{\mathbb{R}}$ tails: a final common step in integrin activation. Science 2003; 302: 103-106.

29. Zhang Z, Vuori K, Reed JR, Ruoslahti $E$. The $\left\langle 5^{\mathbb{R}} 1\right.$ integrin supports survival of cells on fibronectin and up-regulates Bcl-2 expression. Proc Natl Acad Sci USA 1995; 92: $6161-6165$.

30. Matter ML, Ruoslahti E. A signaling pathway from the $\alpha 5 \beta 1$ and $\alpha \mathrm{v} \beta 3$ integrins that elevates bcl-2 transcription. J Biol Chem 2001; 276: 27757-27763.

31. Barlow AJ, Francis-West PH. Ectopic application of recombinant BMP-2 and BMP-4 can change patterning of developing chick facial primordia. Development 1997; 124: $391-398$

32. Nakamura T, Colbert MC, Robbins J. Neural crest cells retain multipotential characteristics in the developing valves and label the cardiac conduction system. Circ Res 2006; 98 : 1547-1554

33. Saga $\mathrm{Y}$, Miyagawa-Tomita S, Takagi A, Kitaijma S, Miyazaki J, Inoue T. MesP1 is expressed in the heart precursor cells and required for the formation of a single heart tube. Development 1999; 126: 3437-3447.

34. Hogan B, Beddington R, Costantini F, Lacy E. Manipulating The Mouse Embryo: A Laboratory Manual. 2nd edn Cold Spring Harbor Laboratory Press: Cold Spring Harbor, NY, USA, 1994

35. Shen MM, Wang H, Leder P. A differential display strategy identifies Cryptic, a novel EGFrelated gene expressed in the axial and lateral mesoderm during mouse gastrulation. Development 1997; 124: 429-442.

36. Belo JA, Leyns L, Yamada G, De Robertis EM. The prechordal midline of the chondrocranium is defective in Goosecoid-1 mouse mutants. Mech Dev 1998; 72: 15-25.

37. Shah NM, Marchionni MA, Isaacs I, Stroobant P, Anderson DJ. Glial growth factor restricts mammalian neural crest stem cells to a glial fate. Cell 1994; 77 : 349-360.

Cell Death and Disease is an open-access journal (icensed under a Creative Commons Attribution-NonCommercial-
licensed ShareAlike 3.0 Unported License. To view a copy of this license, visit http://creativecommons.org/licenses/by-nc-sa/3.0/ 